\title{
Reducibilities of Wüstite and Calcio-wüstite in Terms of High Temperature X-ray Diffraction Analysis
}

\author{
Boyuan CAI, ${ }^{1) *}$ Takashi WATANABE,${ }^{2)}$ Chikashi KAMIJO,${ }^{3)}$ Kohei SUNAHARA, ${ }^{4)}$ Masahiro SUSA ${ }^{2)}$ and \\ Miyuki HAYASHI ${ }^{21}$
}

1) Department of Metallurgy and Ceramics Science, Tokyo Institute of Technology, 2-12-1 Ookayama, Meguro-ku, Tokyo, 1528552 Japan. $\quad 2$ 2) Department of Materials Science and Engineering, Tokyo Institute of Technology, 2-12-1 Ookayama, Meguro-ku, Tokyo, 152-8552 Japan. $\quad 3)$ Technical Research \& Development Bureau, Nippon Steel \& Sumitomo Metal Corporation, 20-1 Shintomi, Futtsu, Chiba, 293-8511 Japan. 4 4) Corporate Research \& Development Laboratories, Sumitomo Metal Industries, Ltd., 16-1 Sunayama, Kamisu, Ibaraki 314-0255 Japan.

(Received on November 9, 2016; accepted on January 4, 2017)

\begin{abstract}
Reducibilities of wüstite and calcio-wüstite have been examined using high temperature X-ray diffraction analysis including the effect of hydrogen on the reducibility. $\mathrm{Fe}_{2} \mathrm{O}_{3}$ reagent powders and hematite ore powders were used for reduction of wüstite (denoted as FeO) and sintered ore powders were used for reduction of $\mathrm{FeO}$ and calcio-wüstite (denoted as $\mathrm{CW}$ ). High-temperature X-ray diffraction was applied to these samples in a flow of $\mathrm{CO}-\mathrm{CO}_{2}-\mathrm{He}$ mixtures with and without 3.9 vol\% of hydrogen during the heating cycle which simulates a blast furnace condition. The diffraction angle was scanned in the range from $33^{\circ}$ to $55^{\circ}$. In experiment on sintered ore powders without hydrogen, the main peak around $48.5^{\circ}$ shifted to lower angles with increasing temperature. This shift also continued while temperature was kept at $1000^{\circ} \mathrm{C}$ where wüstite was saturated with iron; on the contrary, the peak shift did not take place for hematite ore powders. This main peak is associated with wüstite (200), which is actually composed of peaks due to $\mathrm{FeO}$ and $\mathrm{CW}$ for sintered ore powders. The peak shift reflects that the peak intensity of CW increases relative to that of $\mathrm{FeO}$, which suggests that the reduction of $\mathrm{FeO}$ proceeds faster than that of $\mathrm{CW}$, and the reducibility of $\mathrm{FeO}$ is higher. In contrast, the peak shift did not take place in experiment on sintered ore powders with hydrogen additions. This suggests that the reducibility of $\mathrm{CW}$ is comparable to that of $\mathrm{FeO}$ in the presence of hydrogen.
\end{abstract}

KEY WORDS: sintered ore; wüstite; calcio-wüstite; high temperature X-ray diffraction; reduction; hydrogen addition.

\section{Introduction}

Reducibility of sintered ores is one of crucial factors affecting operation stability of a blast furnace ${ }^{1-3)}$ because sintered ores are the main iron source for the furnace. Sintered ores typically consist of four phases: hematite $\left(\mathrm{Fe}_{2} \mathrm{O}_{3}\right)$, magnetite $\left(\mathrm{Fe}_{3} \mathrm{O}_{4}\right)$, calcium ferrite (denoted as $\mathrm{CF}$, mainly silico-ferrite of calcium and aluminium (SFCA)) and slag phases; among them, $\mathrm{Fe}_{2} \mathrm{O}_{3}$ and $\mathrm{CF}$ are in main proportion. Reduction of sintered ores in a blast furnace is very complex because temperature as well as gas components change depending on the position of the furnace. This reduction normally proceeds via two steps: (i) $\mathrm{Fe}_{2} \mathrm{O}_{3}, \mathrm{Fe}_{3} \mathrm{O}_{4}$ and $\mathrm{CF}$ are reduced to wüstite in the lower temperature zone and (ii) wüstite is reduced to metallic iron in the thermal reserve zone and in the even higher temperature zone. The second step is of particular importance in practice because the reaction rate at higher temperatures dominates the overall reduction efficiency of a blast furnace. ${ }^{4-6)}$

\footnotetext{
* Corresponding author: E-mail: cai.b.aa@m.titech.ac.jp DOI: http://dx.doi.org/10.2355/isijinternational.ISIJINT-2016-661
}

There are two types of wüstite in reduced sintered ores: one is wüstite (donated as $\mathrm{FeO}$ ) reduced from hematite containing less impurities and the other is calcio-wüstite (donated as $\mathrm{CW}$ ) reduced from $\mathrm{CF}$ : both $\mathrm{FeO}$ and $\mathrm{CW}$ have the rock-salt structure. $\mathrm{CW}$ contains $\mathrm{CaO}$ and other gang components such as $\mathrm{MgO}, \mathrm{SiO}_{2}$ and $\mathrm{Al}_{2} \mathrm{O}_{3}$ as solutes, and thus its reducibility could be different from that of $\mathrm{FeO}$. Moreover, the phase structure around wüstite would also affect the reducibility of wüstite. For example, wüstite in sintered ores is mostly adhesive to the slag phase, which is an obstacle against reducing gas penetration to wüstite and worsens the reducibility. Thus, it is important to know the effective reducibilities of $\mathrm{FeO}$ and $\mathrm{CW}$ in practical sintered ores.

Many studies have been made on the reducibilities of $\mathrm{FeO}$ and CW. Most researchers have concluded that the reduction rate of wüstite is accelerated in the presence of $\mathrm{CaO} .{ }^{7-11)}$ For example, Inoue et al. ${ }^{8)}$ have reported that the reduction rate of wüstite at $900^{\circ} \mathrm{C}$ and $1000^{\circ} \mathrm{C}$ by $\mathrm{CO}-\mathrm{CO}_{2}$ gas mixture increases with increasing $\mathrm{CaO}$ content in wüstite up to 1 mass $\%$, beyond which it becomes almost constant. They have suggested that the higher reducibility of $\mathrm{CW}$ may be 
due to a larger number of fine pores formed in the reduced layer of $\mathrm{CW}$. Noguchi et al. ${ }^{10)}$ have measured the reduction rate from wüstite to iron at $800^{\circ} \mathrm{C}, 900^{\circ} \mathrm{C}, 1000^{\circ} \mathrm{C}$ and $1100^{\circ} \mathrm{C}$ by high-purity $\mathrm{CO}$ gas using powder mixtures having three different ratios of synthesized SFCA to reagent $\mathrm{Fe}_{2} \mathrm{O}_{3}$. They have found that below $900^{\circ} \mathrm{C}$ the reduction rate is faster with increasing ratio of SFCA to $\mathrm{Fe}_{2} \mathrm{O}_{3}$ but is not dependent on the ratio above $1000^{\circ} \mathrm{C}$. They have implied that the lower reduction rate of $\mathrm{FeO}$ is attributed to the formation of the dense iron layer near the surface; however, the dense iron layer is not formed on the surface of $\mathrm{CW}$ owing to the simultaneous generation of iron and slag. However, to the best of the authors' knowledge, there are few reports on the effective reducibilities of $\mathrm{FeO}$ and $\mathrm{CW}$ in practical sintered ores. This may stem from the difficulty in distinguishing between the reducibilities of $\mathrm{CW}$ and $\mathrm{FeO}$ in practical sintered ores.

In addition, Japanese steel industries are currently developing innovative technology for low reducing agent ratio operation through the Japan's national project COURSE50 ${ }^{12)}$ to reduce $\mathrm{CO}_{2}$ emissions. Hydrogen reduction is one of the main technologies in COURSE50. ${ }^{12)}$ Hence, the effect of hydrogen on the reducibilities of $\mathrm{FeO}$ and $\mathrm{CW}$ also needs to be clarified.

The difference between reducibilities of $\mathrm{FeO}$ and $\mathrm{CW}$ in sintered ores could directly be evaluated using high temperature X-ray diffraction (XRD) analysis because the lattice constant of $\mathrm{CW}$ increases with increasing $\mathrm{CaO}$ concentration in the solid solution even under a constant oxygen partial pressure, ${ }^{13,14)}$ and the diffraction peaks of $\mathrm{FeO}$ and $\mathrm{CW}$ can be distinguished from each other to compare the intensities of these diffraction peaks corresponding to the respective concentrations. Consequently, the aim of this study is to clarify the difference between reducibilities of $\mathrm{FeO}$ and $\mathrm{CW}$ and the effect of hydrogen on the reducibility using high temperature XRD.

\section{Experimental}

\subsection{Sample Preparation}

Samples used in this study were $\mathrm{Fe}_{2} \mathrm{O}_{3}$ reagent powders (diameter: $1 \mu \mathrm{m}$, purity: $99.9 \%$ ), hematite ores and sintered ores. Table 1 summarizes the chemical compositions of the sintered ore and the compositions of $\mathrm{Fe}_{2} \mathrm{O}_{3}$ phase containing $\mathrm{SiO}_{2}$ and $\mathrm{Al}_{2} \mathrm{O}_{3}$ in the hematite ore. Electron probe microanalysis (EPMA) revealed that the hematite ore was composed of three different parts of silica $\left(\mathrm{SiO}_{2}\right), \mathrm{Fe}_{2} \mathrm{O}_{3}$ with negligible amounts of gang minerals and $\mathrm{Fe}_{2} \mathrm{O}_{3}$ containing $\mathrm{SiO}_{2}$ and $\mathrm{Al}_{2} \mathrm{O}_{3}$ as solutes. Some of the hematite ore and sintered ore samples were crushed into fine powders using an alumina mortar and a pestle and were subjected to XRD analysis to determine major constituent phases before heating. This XRD analysis was carried out with $\operatorname{CoK} \alpha$ radiation at an accelerating voltage of $40 \mathrm{kV}$ and a filament current of $250 \mathrm{~mA}$. The optical system of a parallel beam was employed. The scan range was $2 \theta=20-80^{\circ}$ which covered all the compounds in the samples. Figure 1 shows XRD profiles of the hematite ore (a) and the sintered ore (b). The diffraction peaks due to $\mathrm{Fe}_{2} \mathrm{O}_{3}$ and $\mathrm{SiO}_{2}$ are observed for the hematite ore, while the peaks due to $\mathrm{Fe}_{2} \mathrm{O}_{3}, \mathrm{Fe}_{3} \mathrm{O}_{4}$, $\mathrm{CF}$ and dicalcium-silicate $\left(2 \mathrm{CaO} \cdot \mathrm{SiO}_{2}\right.$ denoted as $\left.\mathrm{C}_{2} \mathrm{~S}\right)$ are
Table 1. Chemical compositions of the sintered and hematite ores (mass\%).

\begin{tabular}{|c|c|c|c|c|c|c|c|c|}
\hline & T.Fe & $\mathrm{Fe}_{2} \mathrm{O}_{3}$ & $\mathrm{FeO}$ & $\mathrm{SiO}_{2}$ & $\mathrm{CaO}$ & $\mathrm{Al}_{2} \mathrm{O}_{3}$ & $\mathrm{MgO}$ & $\begin{array}{l}\mathrm{CaO} / \\
\mathrm{SiO}_{2}\end{array}$ \\
\hline $\begin{array}{l}\text { Sintered } \\
\text { ore }\end{array}$ & 56.0 & & 8.19 & 5.27 & 11.56 & 1.84 & 1.27 & 2.19 \\
\hline $\begin{array}{c}\text { Hematite } \\
\text { ore }\end{array}$ & & 97.3 & & 1.9 & & 0.8 & & \\
\hline
\end{tabular}
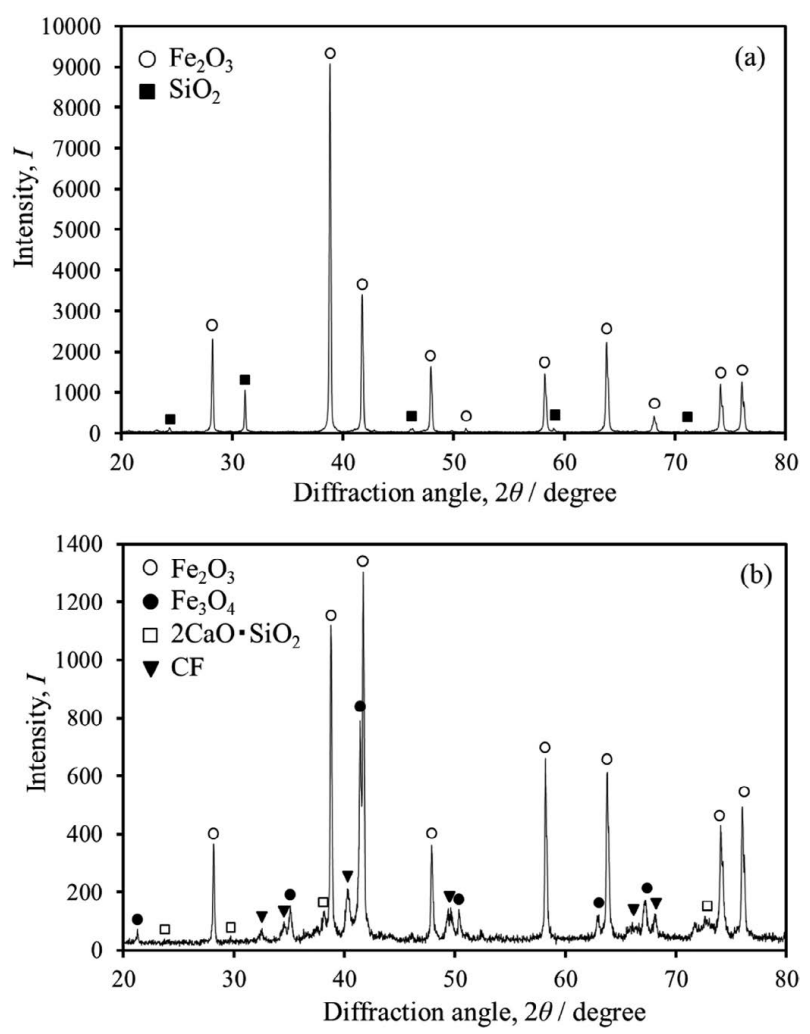

Fig. 1. XRD profiles of hematite ore (a) and sintered ore (b).

observed for the sintered ore.

In order to compare gas reduction rates of the samples, their particle sizes, i.e., their specific surface areas must be identical. It should be noted that the sintered ore is composed of several phases with different strengths and thereby the constituent phases may be different from particle to particle depending on the size. To avoid such a situation, the hematite and sintered ores were crushed and sieved into four different groups with particle size ranges of $<38 \mu \mathrm{m}, 38-75$ $\mu \mathrm{m}, 75-150 \mu \mathrm{m}$ and $150-300 \mu \mathrm{m}$, which were subjected to XRD analysis. Actually the XRD profiles depended on the particle size for the samples larger than $75 \mu \mathrm{m}$. Thus, these samples were further ground into particles finer than $75 \mu \mathrm{m}$. As a result, the XRD profiles of the samples were almost the same as those of the samples sized $<38 \mu \mathrm{m}$ and $38-75 \mu \mathrm{m}$. In this study, only the hematite and sintered ore samples sized $38-75 \mu \mathrm{m}$ were subjected to high temperature XRD analysis.

\subsection{High Temperature XRD Analysis}

Figure 2 shows a schematic diagram of the high-temperature X-ray diffractometer used in this study. About $400 \mathrm{mg}$ of sample powders were mounted into a shallow alumina holder $(17 \mathrm{~mm}$ length $\times 9 \mathrm{~mm}$ width $\times 0.8 \mathrm{~mm}$ depth $)$ and 


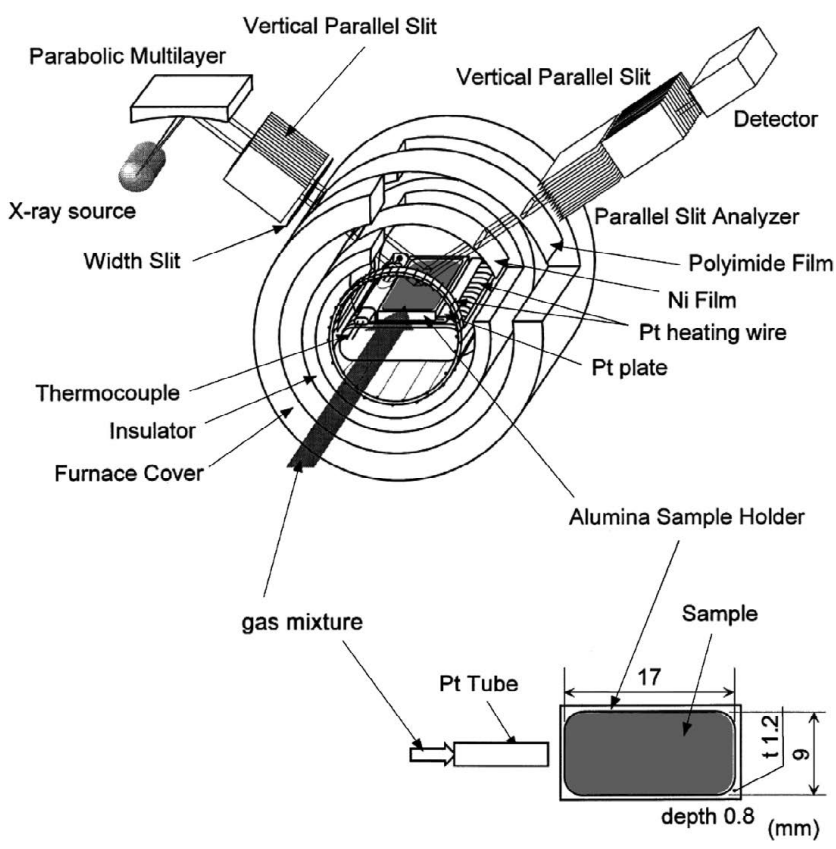

Fig. 2. Schematic diagram of the high-temperature X-ray diffractometer.

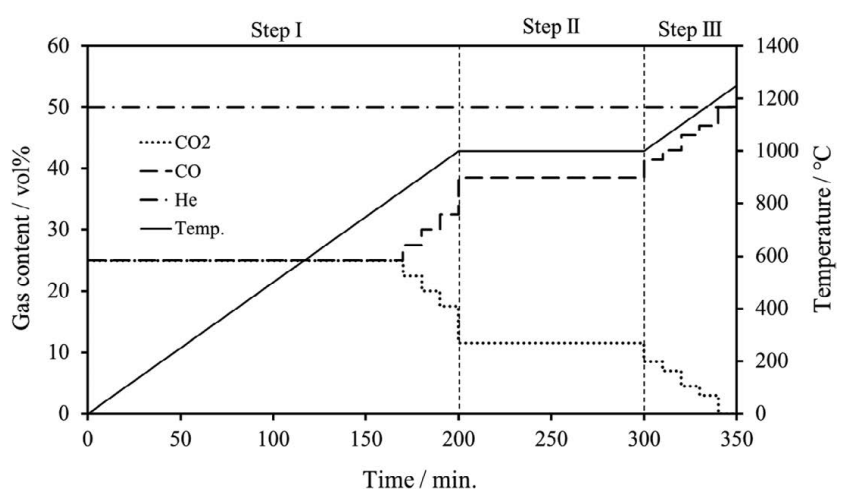

Fig. 3. Experimental conditions of temperature and gas compositions.

then the holder was horizontally placed on the heating plate with Pt heating wire. To protect the sample holder from erosion, an iron foil $0.1 \mathrm{~mm}$ thick was placed under the power sample. Temperature of a sample was measured by an R-type thermocouple next to the sample with the accuracy of $\pm 0.1^{\circ} \mathrm{C}$. The sample chamber was sealed by a Ni film to prevent radiation heat transfer and also by a polyimide film to shield the controlled atmosphere from air.

The maximum power of X-ray generator was $10 \mathrm{~kW}$ (40 $\mathrm{kV}$ and $250 \mathrm{~mA}$ ) and the $\mathrm{CoK} \alpha$ line was used as the $\mathrm{X}$-ray source. The optical system of a parallel beam was employed, by which accurate data were able to be obtained without systematic errors due to variations in the position and flatness of the sample surface during heating. ${ }^{15)}$ The scan range was $2 \theta=33-55^{\circ}$ covering the peaks of the main compounds. The diffraction scan rate was $5 \%$ min and the scan step was $0.02^{\circ}$. The diffraction angle was calibrated by means of the external standard specimen method using high purity silicon powders at room temperature.

Figure 3 shows experimental conditions of temperature and gas compositions. Oxygen partial pressure in the chamber was adjusted using mixtures of $\mathrm{CO} / \mathrm{CO}_{2}$, the ratio of which was changed depending on temperature to simulate a blast furnace condition. In addition, the gas mixture was diluted with 50 vol\% of helium gas to improve X-ray diffraction strength and was introduced to the surface of the sample through a Pt tube (inner diameter: $3.5 \mathrm{~mm}$ ) placed at the center of the front door of the chamber. The total flow rate of the gas mixture was $1.67 \times 10^{-6} \mathrm{~m}^{3} / \mathrm{s}(100 \mathrm{ml} / \mathrm{min})$. The gas mixture was discharged through the hole at the bottom of the reaction chamber to the outside of the system. For reduction experiment with hydrogen, 3.9 vol\% of $\mathrm{H}_{2}$ was also added to the gas mixture. To simulate the condition of the thermal reserve zone, the sample was heated from room temperature to $1000^{\circ} \mathrm{C}$ with a heating rate of $8.33 \times 10^{-2}$ $\mathrm{K} / \mathrm{s}\left(5^{\circ} \mathrm{C} / \mathrm{min}\right)\left(\right.$ Step I), held at $1000^{\circ} \mathrm{C}$ for $100 \mathrm{~min}$ (Step II) and then heated again up to $1250^{\circ} \mathrm{C}$ at a heating rate of $8.33 \times 10^{-2} \mathrm{~K} / \mathrm{s}$ (Step III). During Steps I and III, temperature continuously increased at a heating rate of $8.33 \times 10^{-2}$ $\mathrm{K} / \mathrm{s}$, resulting in a temperature increment of $24^{\circ} \mathrm{C}$ per scan covering $2 \theta=33-55^{\circ}$.

\section{Results}

Figures 4, 5 and 6 show XRD profiles of the $\mathrm{Fe}_{2} \mathrm{O}_{3}$ reagent, hematite ores and sintered ores reduced in atmosphere with no hydrogen addition, respectively, for Step I (4(a), 5(a) and 6(a)), Step II (4(b), 5(b) and 6(b)) and Step III (4(c), 5(c) and 6(c)), where temperature on the right or the left side of Figs. 4(a), 4(c), 5(a), 5(c), 6(a) and 6(c) represents one at which each scan was started for Steps I and III, and time on the left side of Figs. 4(b), 5(b) and 6(b) represents the total time after heating was started. Figure 7 shows XRD profiles of the sintered ores reduced in atmosphere with hydrogen addition for Step I (a), Step II (b) and Step III (c). It can be seen from Figs. 4(a), 5(a), 6(a) and 7(a) for Step I that the peak intensity of $\mathrm{Fe}_{2} \mathrm{O}_{3}$ becomes higher with increasing temperature although the $\mathrm{Fe}_{2} \mathrm{O}_{3}$ concentration should not increase in actuality. This is because X-ray absorptivity due to gas decreases with an increase in temperature due to the decrease in gas density. In the case of the sintered ores, the peak due to $\mathrm{Fe}_{2} \mathrm{O}_{3}$ disappears at temperatures between 462 and $486^{\circ} \mathrm{C}$; instead, the peak due to $\mathrm{Fe}_{3} \mathrm{O}_{4}$ appears between 414 and $438^{\circ} \mathrm{C}$ and disappears between 822 and $846^{\circ} \mathrm{C}$. More importantly, the wüstite peak starts to appear at $726^{\circ} \mathrm{C}$, at which the CF peak disappears; instead, the $\mathrm{C}_{2} \mathrm{~S}$ peaks seem to appear. This suggests the formation of $\mathrm{CW}$ : $\mathrm{CaO}$ and $\mathrm{SiO}_{2}$ dissolved in $\mathrm{CF}$ should form $\mathrm{C}_{2} \mathrm{~S}$ by reaction with the slag phase when $\mathrm{CF}$ is reduced to $\mathrm{CW}$. The peak intensity of wüstite starts to decrease 20 min after the onset of Step II; simultaneously, the Fe peak appears. The wüstite peak completely disappears between 1096 and $1120^{\circ} \mathrm{C}$, as shown in Fig. 4(c) for Step III.

Table 2 summarizes temperatures at which the peaks due to $\mathrm{Fe}_{2} \mathrm{O}_{3}, \mathrm{CF}, \mathrm{Fe}_{3} \mathrm{O}_{4}$, wüstite and $\mathrm{Fe}$ appear and/or disappear for the $\mathrm{Fe}_{2} \mathrm{O}_{3}$ reagent powder, hematite and sintered ore samples, where $\left(+\mathrm{H}_{2}\right)$ represents the measurements with additions of hydrogen. The table also gives the total heating times in the brackets for the peaks to appear or disappear during Step II. The wüstite peak for $\mathrm{Fe}_{2} \mathrm{O}_{3}$ reagent powders disappears during Step II while those of hematite and sintered ore samples remain until Step III. The difference would stem from the difference in the particle sizes of 
ISIJ International, Vol. 57 (2017), No. 4

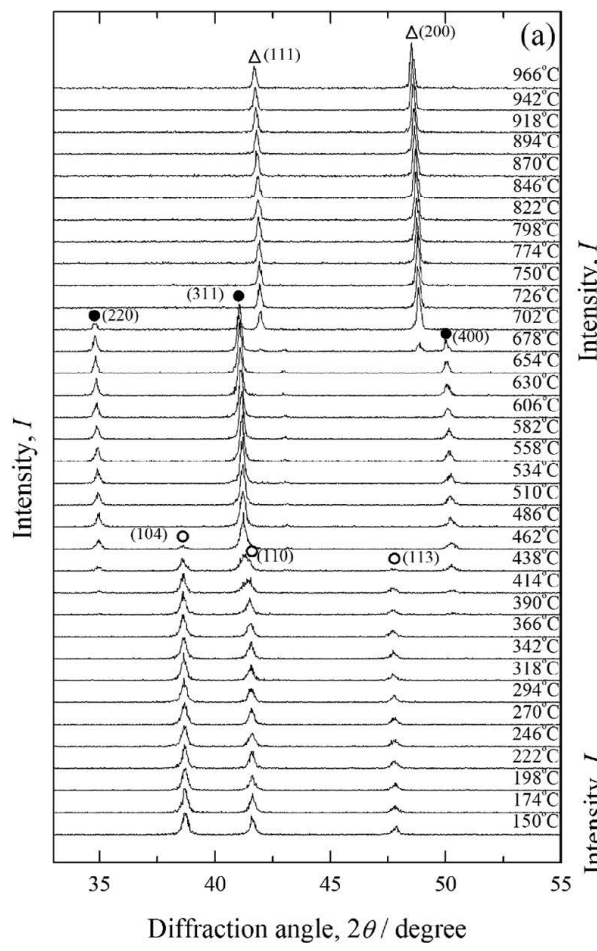

$\mathrm{Fe}_{2} \mathrm{O}_{3}$

$\mathrm{Fe}_{3} \mathrm{O}_{4}$

$\triangle \mathrm{FeO}$
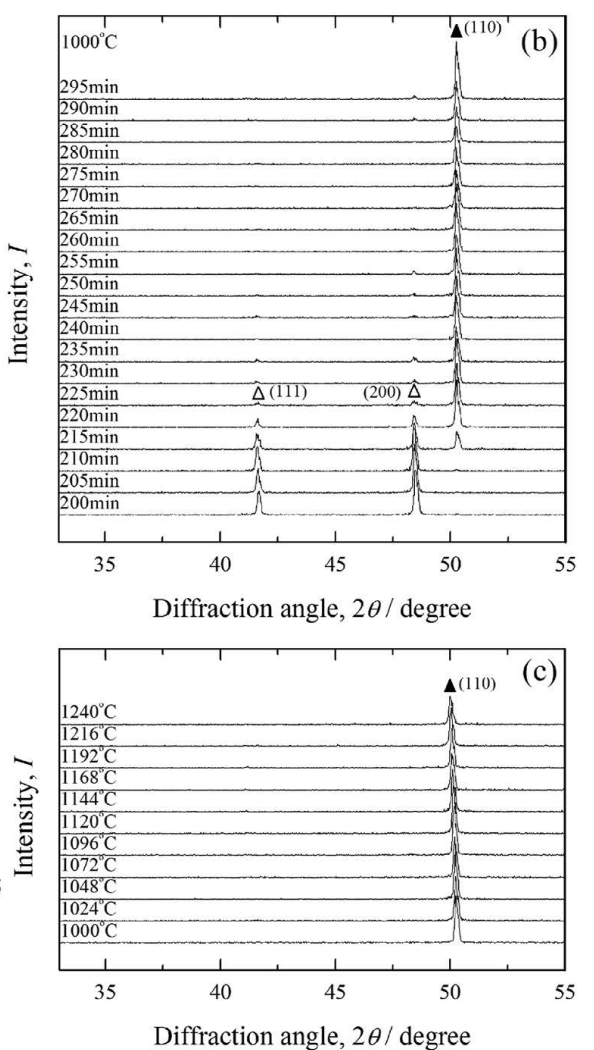

Fig. 4. XRD profiles of the $\mathrm{Fe}_{2} \mathrm{O}_{3}$ reagent reduced in the atmosphere with no hydrogen addition for Step I (a), Step II (b) and Step III (c).

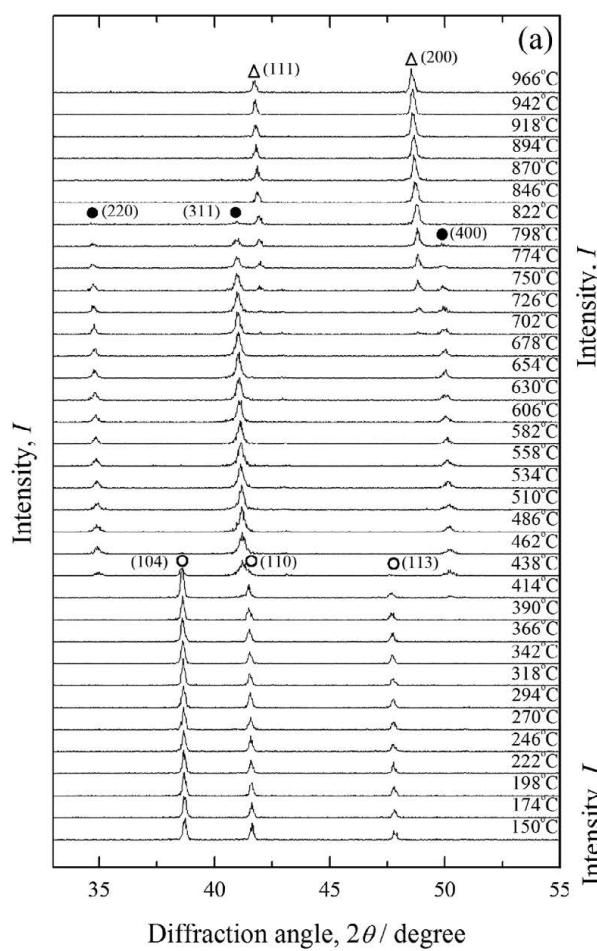

$\bigcirc \mathrm{Fe}_{2} \mathrm{O}_{3}$
$\mathrm{Fe}_{3} \mathrm{O}_{4}$
$\triangle \mathrm{FeO}$
$\triangle \mathrm{Fe}$
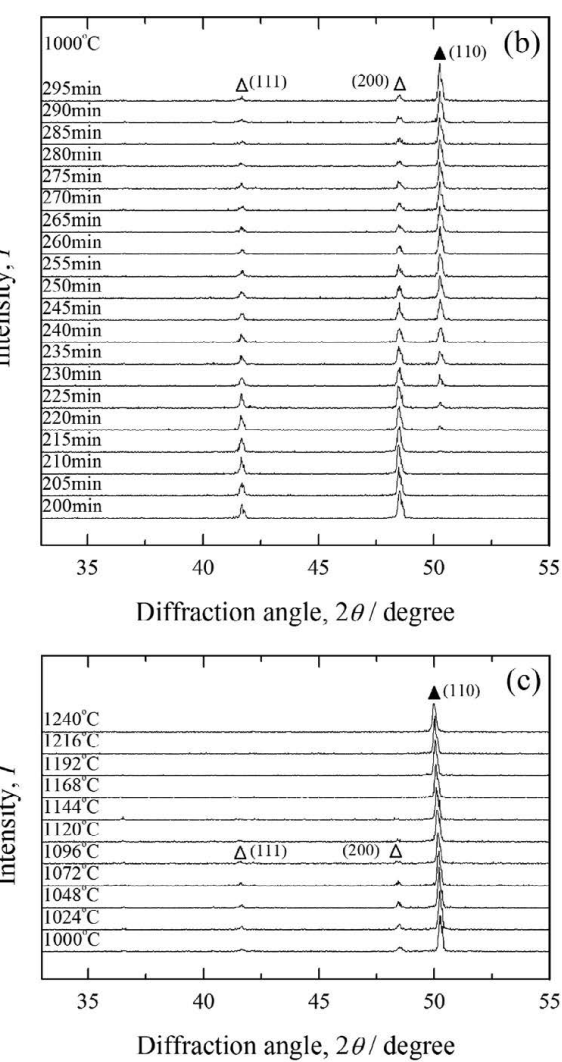

Fig. 5. XRD profiles of the hematite ores reduced in the atmosphere with no hydrogen addition for Step I (a), Step II (b) and Step III (c). 
ISIJ International, Vol. 57 (2017), No. 4
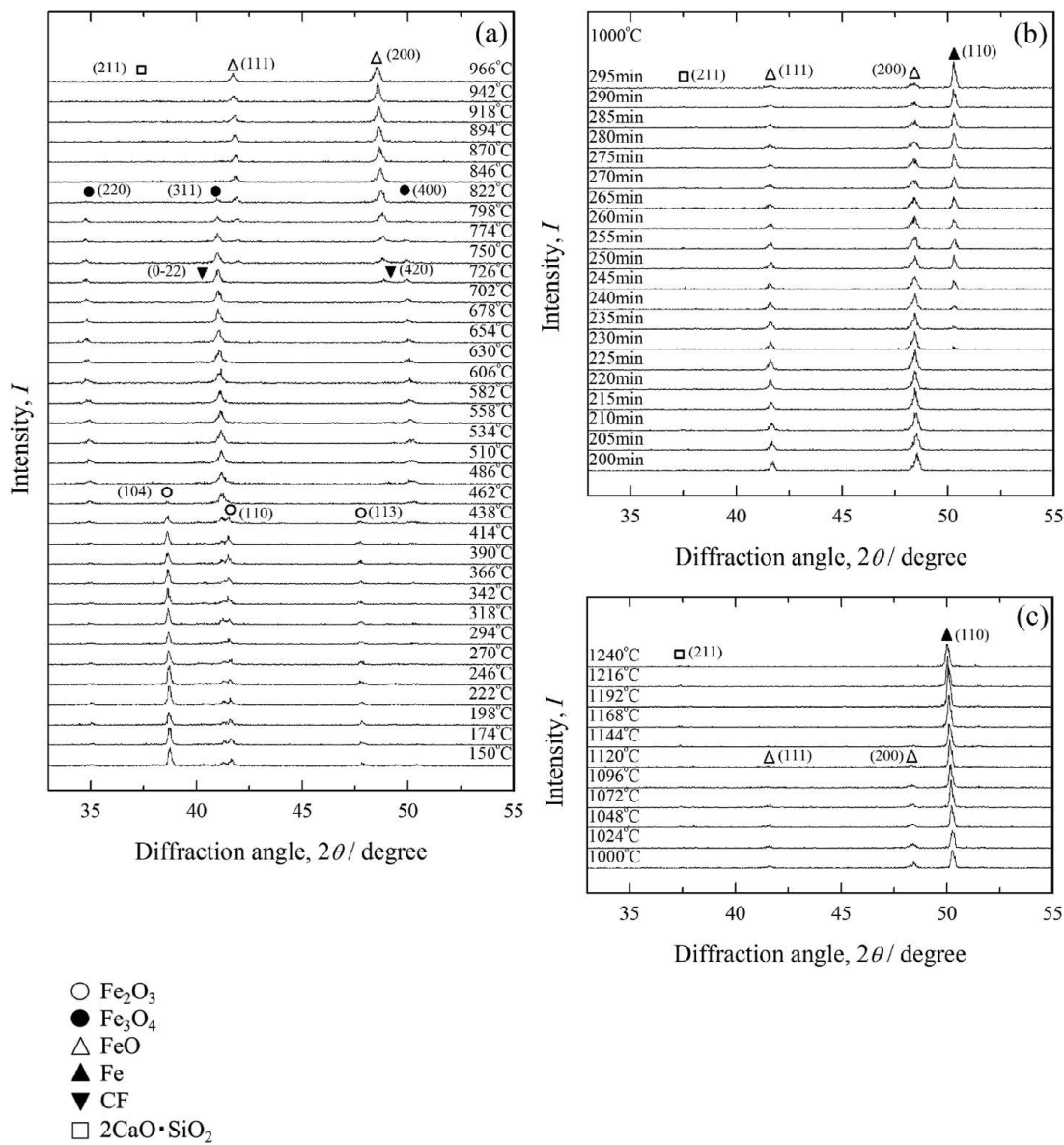

Fig. 6. XRD profiles of the sintered ores reduced in the atmosphere with no hydrogen addition for Step I (a), Step II (b) and Step III (c).
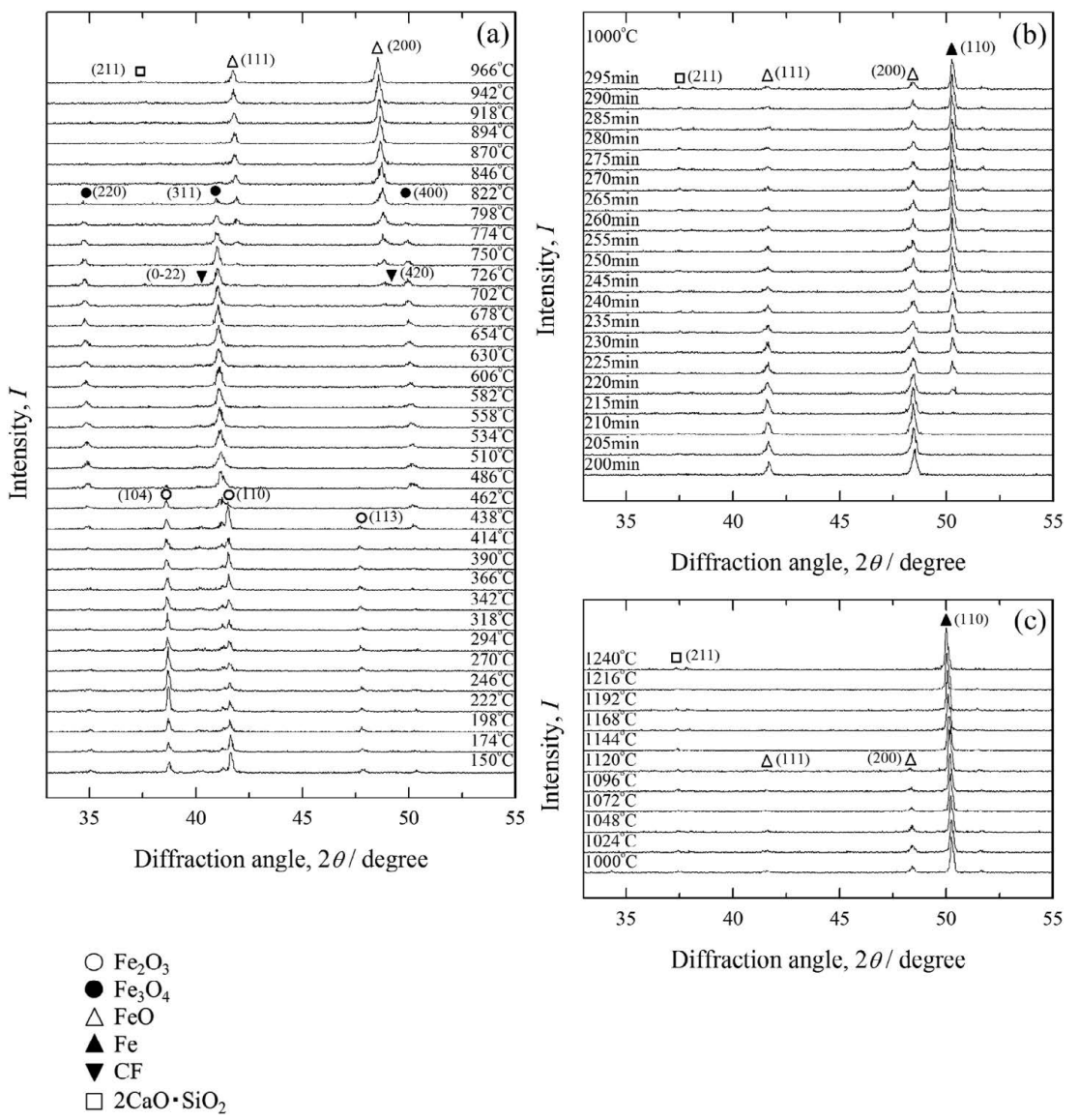

Fig. 7. XRD profiles of the sintered ores reduced in the atmosphere with hydrogen addition for Step I (a), Step II (b) and Step III (c). 
Table 2. Temperatures at which the peaks due to $\mathrm{Fe}_{2} \mathrm{O}_{3}, \mathrm{CF}, \mathrm{Fe}_{3} \mathrm{O}_{4}$, wüstite and $\mathrm{Fe}$ appear and/or disappear for the $\mathrm{Fe}_{2} \mathrm{O}_{3}$ reagent powder, hematite and sintered ore, where $\left(+\mathrm{H}_{2}\right)$ represents the measurements with additions of hydrogen.

\begin{tabular}{|c|c|c|c|c|c|c|c|}
\hline & $\begin{array}{c}\mathrm{Fe}_{2} \mathrm{O}_{3} \\
\text { disappearance }\end{array}$ & $\begin{array}{c}\mathrm{CF}^{*} \\
\text { decomposition }\end{array}$ & $\begin{array}{c}\mathrm{Fe}_{3} \mathrm{O}_{4} \\
\text { appearance/ } \\
\text { increase }\end{array}$ & $\begin{array}{c}\mathrm{Fe}_{3} \mathrm{O}_{4} \\
\text { disappearance }\end{array}$ & $\begin{array}{c}\text { Wüstite } \\
\text { appearance }\end{array}$ & $\begin{array}{c}\text { Wüstite } \\
\text { disappearance }\end{array}$ & $\begin{array}{l}\text { Metallic iron } \\
\text { appearance }\end{array}$ \\
\hline Hematite & $462-486$ & & $390-414$ & $702-726$ & $678-702$ & $1000(229 \mathrm{~min})$ & $1000(214 \mathrm{~min})$ \\
\hline Hematite $\left(+\mathrm{H}_{2}\right)$ & $438-462$ & & $383-390$ & $654-678$ & $654-678$ & 1000 (229 min) & $1000(200 \mathrm{~min})$ \\
\hline Hematite ore & $438-462$. & & $438-462$ & $822-846$ & $726-750$ & $1096-1120$ & $1000(219 \mathrm{~min})$ \\
\hline Sintered ore & $462-486$ & $726-750$ & $414-438$ & $822-846$ & $702-726$ & $1120-1144$ & $1000(229 \mathrm{~min})$ \\
\hline Sintered ore $\left(+\mathrm{H}_{2}\right)$ & $462-486$ & $726-750$ & $414-438$ & $822-846$ & $678-702$ & $1120-1144$ & $1000(219 \mathrm{~min})$ \\
\hline
\end{tabular}

sample powders because the particle size generally gives a great effect on the reduction rate: the particle size of $\mathrm{Fe}_{2} \mathrm{O}_{3}$ sample is $1 \mu \mathrm{m}$ while those of hematite ore and sintered ore samples are $38-75 \mu \mathrm{m}$. Comparison between the results of the measurements with and without hydrogen indicates that wüstite appears at lower temperatures and that $\mathrm{Fe}$ also appears earlier in case of hydrogen additions. This indicates that hydrogen promotes reduction for both hematite and sintered ore samples.

\section{Discussion}

\subsection{Comparison between Reduction Processes from $\mathrm{FeO}$ and $\mathrm{CW}$ to Metallic Iron}

Focus on wüstite (200) peaks to clarify the difference in reducibilities between $\mathrm{FeO}$ and $\mathrm{CW}$. Figure 8 shows close-ups of XRD profiles around wüstite (200) peaks obtained from experiments on $\mathrm{Fe}_{2} \mathrm{O}_{3}$ reagent and sintered ore samples: the former was recorded at $1000^{\circ} \mathrm{C}$ and 14 min after the onset of Step II and the latter at $1000^{\circ} \mathrm{C}$ and 29 min after the onset of Step II. It can be seen that the full width of the half maximum of the peak of the sintered ore sample is larger than that of the $\mathrm{Fe}_{2} \mathrm{O}_{3}$ reagent. This is because $\mathrm{Fe}_{2} \mathrm{O}_{3}$ reagent is reduced to $\mathrm{FeO}$ whereas sintered ore is reduced to $\mathrm{FeO}$ and $\mathrm{CW}$ which contains considerable amounts of gangue components such as $\mathrm{CaO}$ and $\mathrm{SiO}_{2}$ as solutes. Closer look at the peak obtained in the sintered ore sample indicates that it is recorded as superposition of the $\mathrm{FeO}$ and $\mathrm{CW}$ peaks centered at ca. $48.25^{\circ}$ and ca. $48.5^{\circ}$, the former corresponding to $\mathrm{CW}$ because the lattice constant of $\mathrm{CW}$ is greater due to the presence of solutes. This finding is supported by a study due to Inami and Suzuki, ${ }^{13)}$ who have estimated the solubility limit of $\mathrm{CaO}$ in iron saturated wüstite as 5.95 mass $\%$ and the difference between peak angles of $\mathrm{FeO}$ and $\mathrm{CW}$ as $0.55^{\circ}$ at maximum at room temperature.

To investigate the reduction progress of $\mathrm{FeO}$ and $\mathrm{CW}$, the wüstite (200) peaks of the sintered ore sample should be deconvoluted into two peaks. At the moment, however, this deconvolution has not been made because there are no reference data available for $\mathrm{FeO}$ and $\mathrm{CW}$ peak positions. In this study, the total profile around (200) peak is regressed to the Pseudo-Voigt function. The profiles fitted to the PseudoVoigt function are included in Fig. 8.

Figure 9 shows peak areas of wüstite (200) and Fe (110) in the hematite and sintered ore samples as a function of heating time $(t)$ together with the heating profile: the peak area has been derived from the XRD profile regressed to

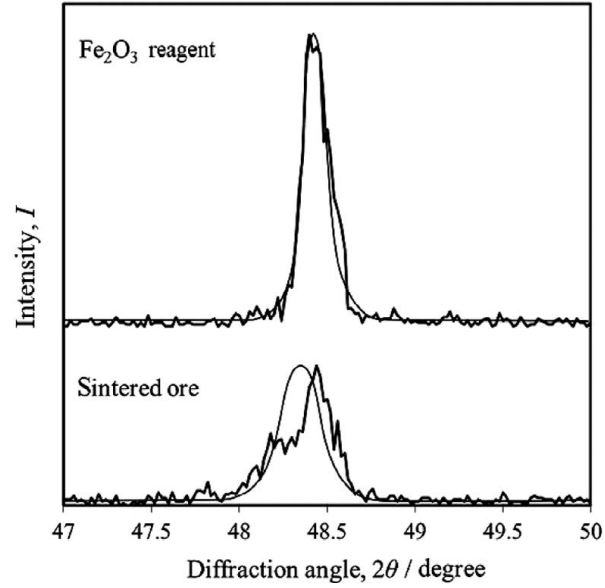

Fig. 8. Close-ups of XRD profiles around wüstite (200) peaks obtained from experiments on $\mathrm{Fe}_{2} \mathrm{O}_{3}$ reagent and sintered ore samples. The profiles fitted to the Pseudo-Voigt function are also included.

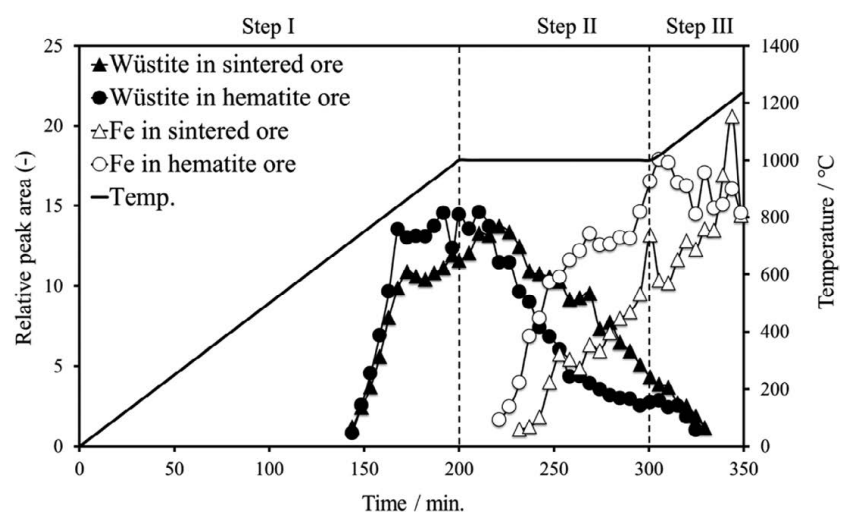

Fig. 9. Peak areas of wüstite (200) and Fe (110) in the hematite and sintered ore samples as a function of heating time $(t)$ together with the heating profile.

the Pseudo-Voigt function and is proportional to the amount of each component. For both hematite and sintered ore samples, the wüstite peaks appear around $t=145 \mathrm{~min}$, i.e., $T=725^{\circ} \mathrm{C}$. The peak areas increase with time and then start to decrease at $t=219 \mathrm{~min}(19 \mathrm{~min}$ after the onset of Step II) for the hematite ore sample and at $t=229 \min (29$ min after the onset of Step II) for the sintered ore sample. In addition, Fe peaks start to appear at the same time when the wüstite peaks start to decrease. This indicates that part of wüstite is reduced to metallic iron and is saturated with Fe. Figure 9 also indicates that the reduction of wüstite in the hematite ore sample proceeds faster than that in the 
sintered ore sample.

Figure 10 shows changes with time of the diffraction angles of wüstite (200) peaks for the hematite and sintered ore samples together with the heating profile, where the diffraction peak angle has been derived from the XRD profile regressed to the Pseudo-Voigt function. With respect to the hematite ore, the diffraction peak angle decreases with time from $t=145 \mathrm{~min}$ in Step I at which time wüstite appears to $t=219$ min in Step II at which time wüstite becomes saturated with iron. During this process, the decrease in diffraction peak angle stems from the thermal expansion of lattice constant as well as the change of non-stoichiometry of FeO, i.e., the decrease in the value of $x$ in $\mathrm{Fe}_{1-\mathrm{x}} \mathrm{O}$. Subsequently, the diffraction peak angle keeps constant up to the onset of Step III. This is because neither the thermal expansion of lattice constant nor the decrease in the value of $x$ takes place. In Step III, the diffraction peak angle decreases with time again owing to the thermal expansion of lattice constant during the heating cycle. With respect to the sintered ore, in contrast, the diffraction peak angle always decreases even when wüstite is saturated with iron at $1000^{\circ} \mathrm{C}$ although the negative gradient becomes moderate. This decrease in the diffraction peak angle would be associated with the variation in the peak intensities of $\mathrm{FeO}$ and $\mathrm{CW}$.

Figure 11 shows a conceptual illustration to explain how the diffraction peak angle decreases owing to the variation of the peak intensities of $\mathrm{FeO}$ and $\mathrm{CW}$. As aforementioned, the total peak of wüstite (200) consists of the peaks of $\mathrm{FeO}$ and $\mathrm{CW}$ and the diffraction angle of the $\mathrm{CW}$ peak is smaller than that of the FeO peak. Now consider that the decreasing rate of the peak intensity of $\mathrm{FeO}$ is larger than that of $\mathrm{CW}$, as shown in Fig. 8, which indicates that the diffraction angle of the total peak shifts to lower angles. As a consequence, the decrease in the diffraction peak angle during Step II for the sintered ore sample in Fig. 7 is due to the increase in the peak intensity of $\mathrm{CW}$ relative to that of $\mathrm{FeO}$, suggesting that a considerable amount of CW still remained during Step II. Both Figs. 10 and 11 suggest that the reduction of FeO proceeds faster than that of $\mathrm{CW}$, i.e., the reducibility of $\mathrm{FeO}$ is higher than that of $\mathrm{CW}$. This result is inconsistent with the most previous studies: As aforementioned, Noguchi et $a l .{ }^{10)}$ have reported that the reduction rates of $\mathrm{CW}$ and $\mathrm{FeO}$ are almost the same above $1000^{\circ} \mathrm{C}$. The reason for this inconsistency may be due to the fact that the effective reducibilities of $\mathrm{FeO}$ and $\mathrm{CW}$ are measured for practical sintered

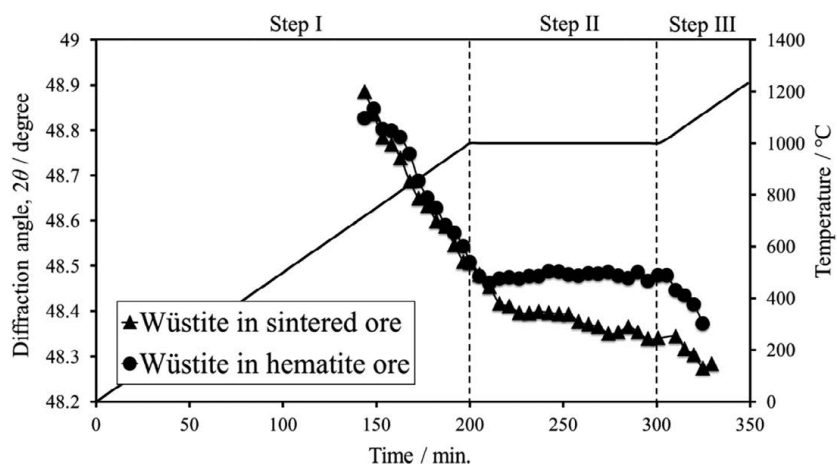

Fig. 10. Changes with time of the diffraction angles of wüstite (200) peaks for the hematite and sintered ore samples together with the heating profile. ores in this study. In fact, the phase structure around wüstite would affect the reducibility of wüstite. It is known that skeleton hematite in sintered ores causes the pulverization of ores around 400 to $700^{\circ} \mathrm{C}$ in a blast furnace because of the volume expansion from $\mathrm{Fe}_{2} \mathrm{O}_{3}$ to $\mathrm{Fe}_{3} \mathrm{O}_{4} \cdot{ }^{16)}$ Adhesive slag surrounding $\mathrm{Fe}_{2} \mathrm{O}_{3}$ might be cracked, and open pores might be formed so as to enable the reducing gas to directly reach the $\mathrm{FeO}$ phase. However, the reason why the reducibility of $\mathrm{FeO}$ is higher than that of $\mathrm{CW}$ should be studied based on the structural observations.

\subsection{Effect of Hydrogen Additions on Reduction Pro- cess from $\mathrm{FeO}$ and $\mathrm{CW}$ to Metallic Iron}

Figure 12 shows peak areas of wüstite (200) and Fe (110) for the sintered ore samples as a function of heating time, obtained in reduction experiments with and without hydrogen additions, together with the heating profile: the

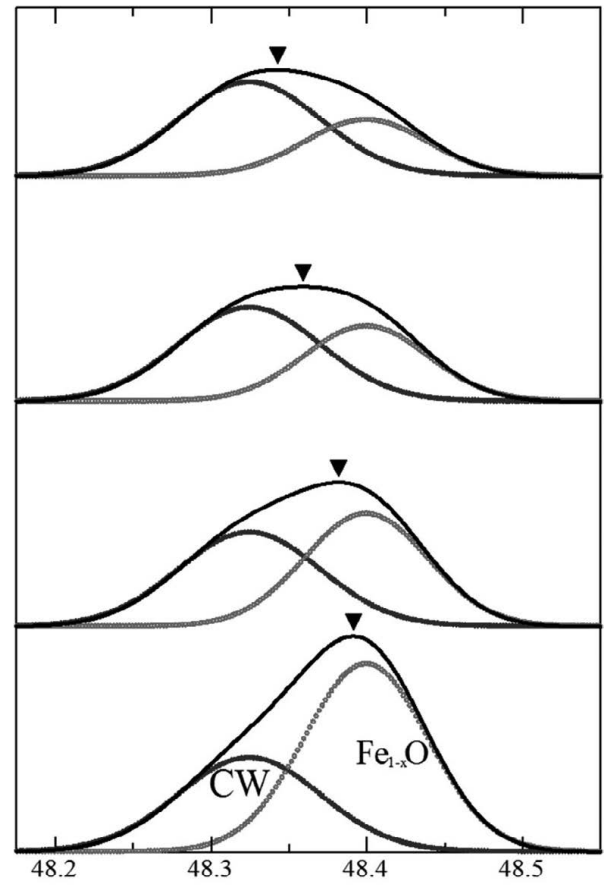

Diffraction angle, $2 \theta /$ degree

Fig. 11. Conceptual illustration to explain how the diffraction peak angle decreases owing to the variation of the peak intensities of $\mathrm{FeO}$ and $\mathrm{CW}$.

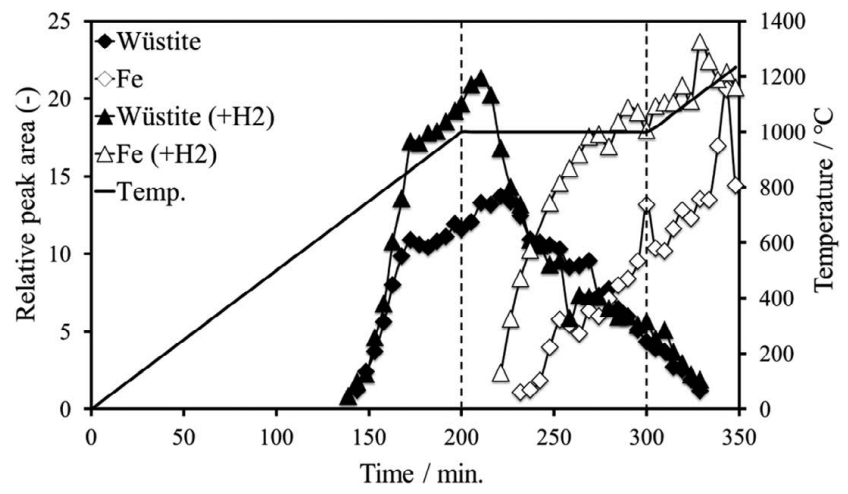

Fig. 12. Peak areas of wüstite (200) and Fe (110) for the sintered ore samples as a function of heating time, obtained in reduction experiments with and without hydrogen additions, together with the heating profile. 


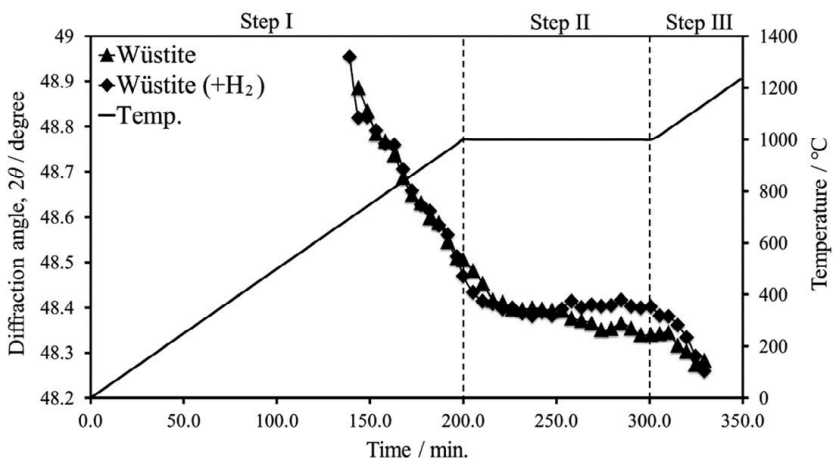

Fig. 13. Changes with time in the diffraction angles of wüstite (200) peaks derived from reduction experiments on the sintered ore samples with and without hydrogen additions.

peak area has been derived from the XRD profile regressed to the Pseudo-Voigt function. It can be seen that the relative area of the wüstite peak reaches the maximum in about 10 min earlier with hydrogen additions than without hydrogen additions. Besides, it can also be seen that the reduction rate of wüstite with hydrogen additions is faster than that without hydrogen additions. These results suggest the possibility that hydrogen additions promote the reducibility of sintered ores. To examine the effect of hydrogen additions from the viewpoint of the peak shift in the same manner as Fig. 10, the changes with time in the diffraction angles of wüstite (200) peaks are compared in Fig. 13, which shows the data derived from reduction experiments on the sintered ore samples with and without hydrogen additions, where the diffraction peak angle has been derived from the XRD profile regressed to the Pseudo-Voigt function.

In case of no hydrogen additions, as mentioned in 4.1, the diffraction peak angle always decreases even after wüstite is saturated with iron at $1000^{\circ} \mathrm{C}$, suggesting that a considerable amount of CW still remained during Step II. In case of hydrogen additions, in contrast, the diffraction peak angle does keep constant for the same period. This indicates that the reduction rate of $\mathrm{CW}$ is comparable to that of $\mathrm{FeO}$, which suggests that the reduction of $\mathrm{CW}$ is accelerated by hydrogen additions, i.e., the reducibility of CW is comparable to that of $\mathrm{FeO}$ in the presence of hydrogen. Sasaki and Hida have reported that the needle like calcium ferrite that is a type of calcium ferrites is surrounded by fine pores. ${ }^{17)}$ It is considered that hydrogen more easily penetrates through such fine pores rather than carbon monoxide owing to the smaller molecular size of hydrogen.

\section{Conclusions}

High-temperature X-ray diffraction analysis has been applied to $\mathrm{Fe}_{2} \mathrm{O}_{3}$ reagent powders, hematite ore powders and sintered ore powders to examine the reducibilities of $\mathrm{FeO}$ and $\mathrm{CW}$ in $\mathrm{CO}-\mathrm{CO}_{2}-\mathrm{He}$ with and without hydrogen. Examination was carried out based on the fact that wüstite produced from $\mathrm{Fe}_{2} \mathrm{O}_{3}$ reagent and hematite ore powders contains only $\mathrm{FeO}$ whereas wüstite produced from sintered ore powders contains both $\mathrm{FeO}$ and $\mathrm{CW}$. The samples were heated up to $1000^{\circ} \mathrm{C}$ at a rate of $8.33 \times 10^{-2} \mathrm{~K} / \mathrm{s}$ (Step I), held at $1000^{\circ} \mathrm{C}$ for $100 \mathrm{~min}$ (Step II) and then increased up to $1250^{\circ} \mathrm{C}$ at a rate of $8.33 \times 10^{-2} \mathrm{~K} / \mathrm{s}$ (Step III) to simulate a blast furnace condition.

The findings and conclusions obtained are summarized as follows:

(1) The wüstite peak for $\mathrm{Fe}_{2} \mathrm{O}_{3}$ reagent powders disappears during Step II while those of hematite and sintered ore samples remain until Step III. The difference would stem from the difference in the particle sizes of sample powders (the particle size of $\mathrm{Fe}_{2} \mathrm{O}_{3}$ sample is about $1 \mu \mathrm{m}$ while those of hematite ore and sintered ore samples are in the range 38-75 $\mu \mathrm{m})$.

(2) The diffraction peak of wüstite (200) reduced from sintered ore consists of those of $\mathrm{FeO}$ and $\mathrm{CW}$. The relative intensities of these peaks affect the diffraction angle of the total peak of wüstite, which shifts to lower angles even while wüstite is saturated with iron at $1000^{\circ} \mathrm{C}$ (Step II) where the peak intensity of $\mathrm{CW}$ increases relative to that of $\mathrm{FeO}$.

(3) In reduction experiment on the sintered ore sample with no hydrogen additions, the diffraction peak angle decreases even while wüstite is saturated with iron at $1000^{\circ} \mathrm{C}$ (Step II), suggesting that the reduction of $\mathrm{FeO}$ proceeds faster than that of $\mathrm{CW}$ and that the reducibility of $\mathrm{FeO}$ is higher.

(4) In reduction experiment on the sintered ore sample with hydrogen additions, the diffraction peak angle keeps almost constant while wüstite is saturated with iron at $1000^{\circ} \mathrm{C}$, suggesting that the reducibility of $\mathrm{FeO}$ is comparable to that of $\mathrm{CW}$ in the presence of hydrogen.

\section{Acknowledgement}

The present work was carried out as a part of COURSE50 project. The authors are thankful to the New Energy and Industrial Technology Development Organization (NEDO) and the Japan Iron and Steel Federation (JISF) for their financial support.

\section{REFERENCES}

1) K. Sato, S. Suzuki, Y. Sawamura and K. Ono: Tetsu-to-Hagané, 68 (1982), 2215.

2) N. Sakamoto, H. Fukuyo, Y. Iwata and T. Miyashita: Tetsu-toHagané, 70 (1984), 504.

3) T. Maeda and Y. Ono: Trans. Iron Steel Inst. Jpn., 25 (1985), 1191.

4) Y. Yamaoka, H. Hotta and S. Kajikawa: Tetsu-to-Hagané, 66 (1980), 1850.

5) K. Mori, R. Hidaka and Y. Kawai: Tetsu-to-Hagané, 66 (1980), 1287.

6) H. Kokubu, A. Sasaki, S. Taguchi and N. Tsuchiya: Tetsu-to-Hagané, 68 (1982), 2338.

7) S. Khalafalla and P. Weston: Trans. TMS-AIME, 239 (1967), 1494

8) H. Inoue, Y. Kiritani and Y. Takahashi: Bull. Res. Inst. Miner. Dressin. Metall., 31 (1975), 118.

9) M. Moukassi, M. Gougeon, P. Steinmetz, B. Dupre and C. Gleitzer: Metall. Trans. B, 15B (1984), 383.

10) D. Noguchi, K. Ohno, T. Maeda, K. Nishioka and M. Shimizu: Tetsuto-Hagané, 98 (2012), 55.

11) Y. Iguchi and S. Hayashi: Tetsu-to-Hagané, 79 (1993), 431.

12) T. Miwa, H. Okuda, M. Osame, S. Watakabe and K. Saito: EECRMETEC InSteelCon 2011, Steel Institute VDEh, Düsseldorf, (2011), Session 1, CD-ROM.

13) T. Inami and K. Suzuki: ISIJ Int., 42 (2002), 150.

14) T. Inami and K. Suzuki: ISIJ Int., 43 (2003), 314.

15) T. Mitsunaga and M. Saigo: Powder Diffr., 3 (2002), 173.

16) H. Nogami, Y. Ueki, T. Murakami and S. Ueda: Tetsu-to-Hagané, 100 (2014), 227.

17) M. Sasaki and Y. Hida: Tetsu-to-Hagané, 68 (1982), 563. 